\title{
El projecte Prat de la Riba: una aposta per a l'augment de vocacions cientificotècniques entre els joves
}

\author{
Eva Valero \\ Coordinadora del projecte Prat de la Riba, Centre de Recerca per a l'Educació Científica i Matemàtica - UAB \\ evalero@pratdelariba.cat
}

El desinterès dels joves pels estudis tècnics o científics és un fet real que ens ha de fer pensar a portar a terme iniciatives que ajudin a canviar aquesta situació. Per contribuir a l'augment de vocacions cientificotècniques, el Centre de Recerca per a l'Educació Científica i Matemàtica (CRECIM) ha posat en marxa el projecte Prat de la Riba. Aquest projecte permet que l'alumnat d'ESO treballi en el marc de l'assignatura de Tecnologia en un context real, a partir de visites a centres industrials. El material didàctic que el projecte proposa està plantejat com a complement del treball a l'aula i com una ajuda per a treballar punts concrets del currículum de l'assignatura. Així, es proposa a l'alumnat un treball a realitzar en tres moments diferents: abans, durant i després de la visita, i que planteja inicialment una situació problema que podria ser real per a l'empresa en qüestió. Per a resoldre aquesta situació l'alumnat ha d'organitzar-se per grups anomenats d'experts i realitzar les activitats que convergeixen en un treball de síntesi i/o de creació.

Paraules clau: tecnologies, ESO, visites, centres industrials

\section{Introducció}

Ja fa molts anys que des de la Comissió Europea s'intenta fomentar l'interès pels estudis de les Ciències i la Tècnica per tal d'assolir els objectius de Lisboa en el 2010. En aquest marc s'han portat a terme moltes iniciatives de les que mostrem a continuació alguns exemples. Durant el 2004, l'entitat DG Research va organitzar el Congrés titulat Europe needs more scientists i també durant el període 2003-2005, l'entitat DG Educació i Cultura va organitzar el Grup Mathematics, Science and Technology Working Group, així com el subgrup Partnership University-School en els quals va participar la responsable del Centre de Recerca per a l'Educació Científica i Matemàtica (CRECIM), Roser Pintó. Una de les àrees temàtiques del programa Science and Society, tant en el cas del 6è com del 7è Programa Marc, va dirigit precisament a Young People, Science Education and Careers.
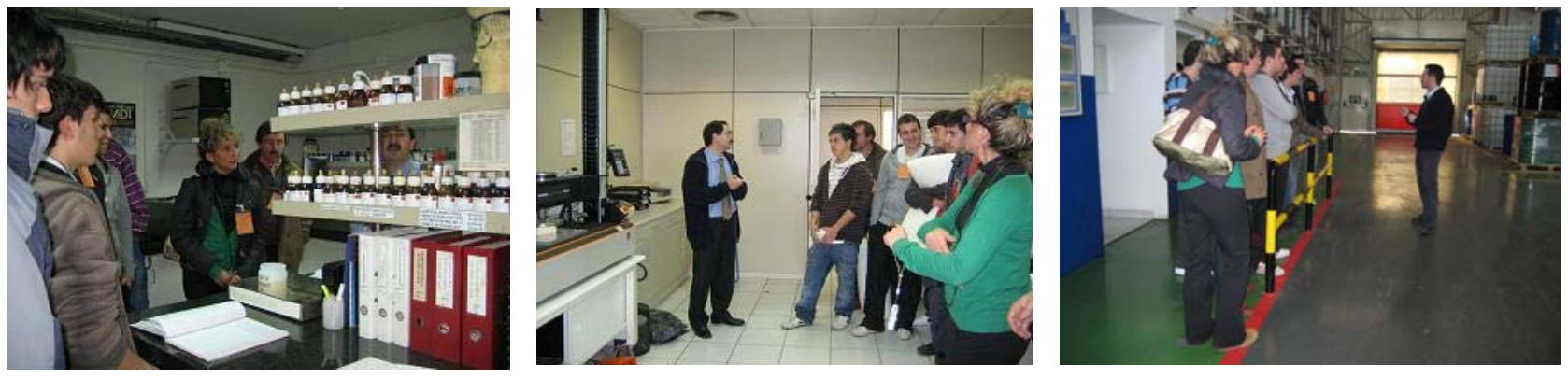
Actualment en el nostre país la realització d'aquesta sèrie d'activitats orientades a estimular el coneixement de la ciència i la tècnica són necessàries. Com si fos una novetat, en els mitjans apareixen sovint dades i comentaris sobre la disminució progressiva del nombre d'estudiants en les enginyeries i en les diferents llicenciatures de Ciències. Diversos exemples reveladors de l'impacte que ha tingut aquest assumpte es poden veure en notícies aparegudes a la premsa (La Vanguardia, 2/4/2008, Europa Press, 2/4/2008, Diari Avui, 31/3/2008).

Per contribuir a la solució del desinterès pels estudis cientificotècnics s'estan promovent accions distintes i complementàries. Per exemple, les que està promovent el Departament d'Innovació, Universitats i Empresa de la Generalitat de Catalunya (pla EnginyCat), millorant l'oferta curricular en les escoles d'Enginyeria i moltes altres que s'estan dissenyant en diferents comunitats.

La disminució del nombre de joves que opten pels estudis cientificotècnics té moltes facetes i, per això accions orientades des d'angles diferents són possibles i desitjables, abordant aspectes diferents de la mateixa problemàtica i adreçant-se a diferents col-lectius.

\section{El projecte Prat de la Riba}

Una de les accions orientada als més joves de la secundaria és el projecte Prat de la Riba que ofereix a l'alumnat de Secundària de Catalunya l'oportunitat de conèixer de prop alguns dels processos productius i pugui imaginar el seu futur professional en aquell marc.

\section{Públic destinatari}

El projecte Prat de la Riba està dirigit principalment a l'alumnat de Secundaria de 13 a 16 anys (ESO) en el marc de l'assignatura de Tecnologia, tot i que es preveu que també hi haurà grups de Batxillerat (16 a 18 anys) que sol-licitin les visites amb l'objectiu d'enfocar alguns dels treballs de recerca.

\section{Àmbit geogràfic de les visites}

Durant el curs 2009-2010 està prevista la visita a 20 centres industrials situats principalment a les comarques del Vallès Oriental, Vallès Occidental, Baix Llobregat i Bages, tot i que també hi ha empreses participants situades a les comarques del Barcelonès i d'Osona. S'espera durant aquest ma- teix curs la incorporació de 20 centres industrials més, situats a altres comarques de la resta de Catalunya.

\section{Objectius}

L'objectiu principal d'aquest projecte és estimular entre els joves l'interès cap a la ciència i la tècnica i, amb això, augmentar el nombre d'estudiants en les carreres científiques i d'enginyeries. Tot això va encaminat a proveir el país de més professionals amb una sòlida formació cientificotecnològica que faci possible una investigació de qualitat, unes innovacions intel-ligents $i$, en definitiva, el progrés tecnològic de Catalunya. Per això l'acció va dirigida principalment als estudiants de secundària (joves de 13 a 16 anys) que encara no han decidit el seu futur professional. Mitjançant la visita a empreses i indústries amb destacables departaments d'I+D+ i, es tracta que coneguin de primera mà:

- les aplicacions de la ciència i la tecnologia en indústries específiques

- el paper clau que tenen els científics i els enginyers en aquestes indústries

- un procés industrial complet en el qual els punts anteriors tinguin la seva màxima expressió

\section{Plantejament de les visites}

Les visites que s'organitzen estan adreçades a l'aprenentatge d'alguns punts o temes del currículum de l'assignatura de Tecnologia (propietats o disseny de productes, característiques de processos industrials...) com un complement al treball d'aula, per aprofundir en temes que s'hi tracten o també com un recurs per orientar algun treball de recerca de Batxillerat o projecte de recerca de quart d'ESO.

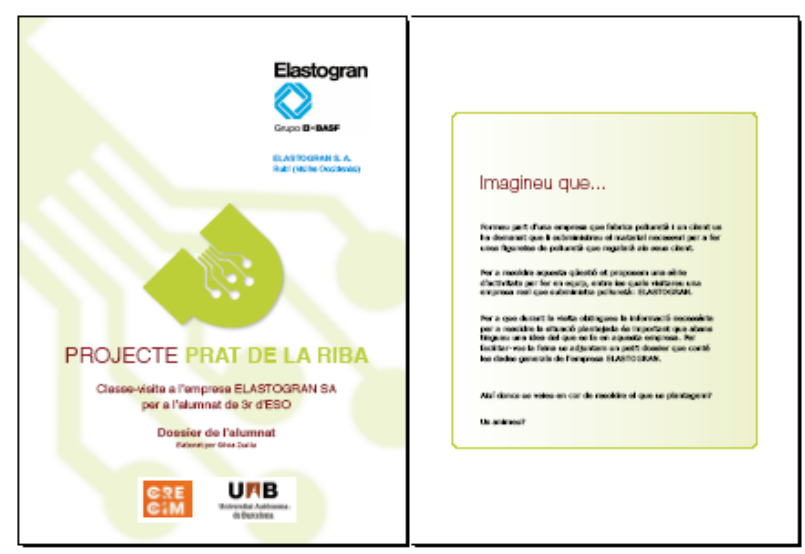


Pel que fa a les orientacions didàctiques del treball a elaborar per l'alumnat hi ha tres punts que són especialment innovadors:

\section{a) Treball de resolució de problemes o mètode d'indagació}

El treball de l'alumnat (dossier de l'alumnat) es planteja com un treball d'indagació guiat per una pregunta o interrogant general ("la pregunta guia"), no com un conjunt preguntes esglaonades. Ja sabem que l'alumnat pot anar seguint cada pregunta individual sense tenir una visió global "cap on va", sense haver aclarit el que realment li interessa buscar i saber. A més s'ha comprovat que els treballs en què l'alumnat sap el que busca i porta la iniciativa afavoreixen la comprensió i fomenten la creativitat.

\section{b) Estructura del treball en tres fases}

Degut a que aquestes classes-visita es plantegen com un recurs didàctic de l'assignatura que va més enllà de la mera visita a unes instal-lacions industrials, el treball està plantejat en tres moments diferents de treball:

\section{- Treball previ a la visita}

Realitzat a l'aula, formant part de l'assignatura de Tecnologia, es duran a terme activitats de preparació als continguts sobre els quals versarà la visita $i$ ja dissenyades per a la resolució d'una Pregunta guia o situació problema que es planteja a l'inici.

\section{- Treball "in situ"}

Seguint un itinerari acordat amb l'empresa, l'alumnat observarà i recollirà informació sobre el tema curricular lligat a la visita (procés tecnològic, procés industrial, comunicacions, etc.) i sobre el treball als laboratoris d'I+D+i de l'empresa visitada.

\section{- Treball posterior a la visita}

Es durà a terme un treball de síntesi i un treball de creació vinculats al procés industrial de l'empresa visitada. A final de curs s'exposaran públicament $\mathrm{i}$

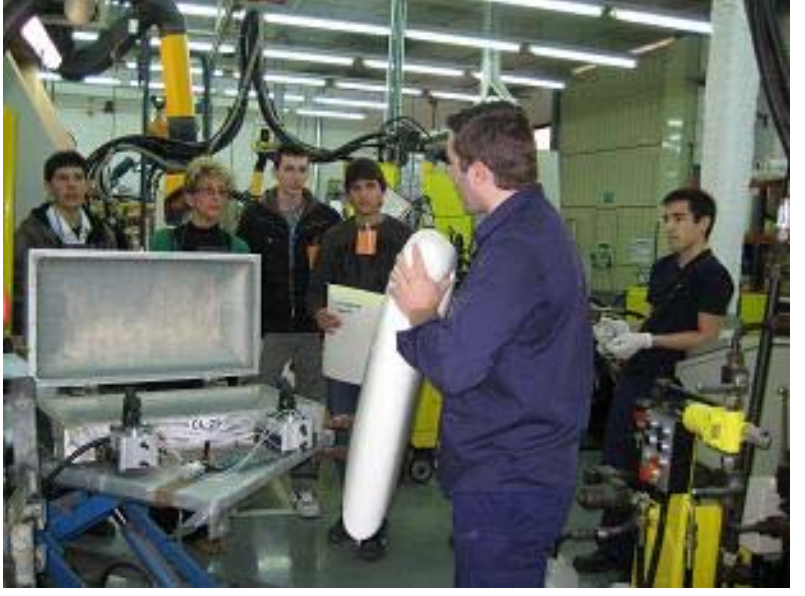

s'atorgaran els Premis Prat de la Riba als millors treballs de creació dels centres participants.

\section{c) Gestió del grup. El mètode d'experts}

La distribució de tasques de l'alumnat durant tot el procés convé organitzar-la de tal manera que s'arribi a resoldre la pregunta guia en grups de 40 5 persones que discutiran en equip i resoldran la situació problema a partir de la cerca d'informació individual des de 4 o 5 perspectives professionals diferents (representades pels diferents "experts").

El grup classe està gestionat per tal que l'alumnat treballi i arribi a les fites que ens proposem, mitjançant el "mètode d'experts" entès com la formació a partir del grup classe en grups de treball més petits i en el repartiment de tasques entre els mem-

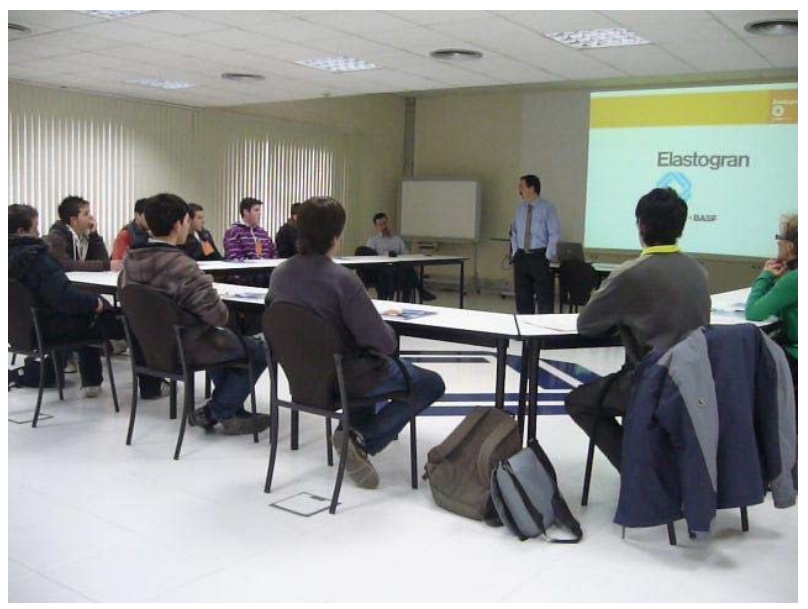

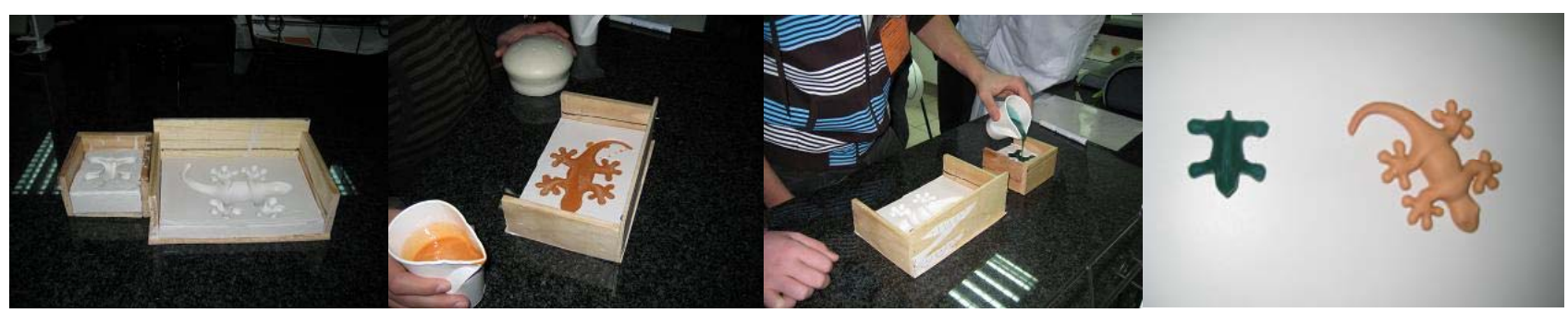


bres del mateix equip. Cada membre de l'equip explora per aprofundir en un aspecte i posteriorment es reuneix l'equip sencer per tal de resoldre la situació problema que només es podrà fer amb la contribució de la feina de cada expert.

Les activitats de l'alumnat no es plantegen com un treball individual fet com a "deures" a casa sense visió de tasca conjunta d'un equip; està ben comprovat que l'alumnat aprèn millor si ho discuteix dins d'un equip. Llavors, si cadascun ha de ser expert en alguna cosa, té les seves responsabilitats i va buscant el que necessita.

Alguns dels experts que es proposen als diferents treballs són:

- Científic (físic, químic, biòleg, etc.)

- Tècnic (enginyer, tècnic) per dissenyar el procés industrial

- Tècnic (enginyer, tècnic) per control de la producció

- Expert en control del producte

- Expert de control de qualitat o expert en R+D+i

\section{d) Els processos d'investigació i desenvolupament, pedra angular de la visita}

Donats el objectius del Projecte Prat de la Riba, l'alumnat que realitza les visites a les empreses, rebra informació específica sobre les tasques que es realitzen en el departament de $R+D+i$. Convé destinar part de la visita a mostrar a l'alumnat en què podria consistir el seu futur professional en tasques cientificotècniques.

Donada la limitació de temps, es preveu en aquestes visites deixar a un segon pla els aspectes sociològics propis de l'estudi d'una empresa i dels seus diversos departaments, com ara Finances, Màrqueting, Recursos Humans, etc.

En tornar de la visita, en tots els cursos es construeix una idea i s'obté un producte final (objecte, material, enginy, solució tècnica, pòster...) que serà exposat. És el Treball de síntesi i el Treball de creació. La disposició de l'alumnat per aquest treball, i també els resultats obtinguts, són aspectes rellevants per avaluar si l'alumnat ha aconseguit els objectius.
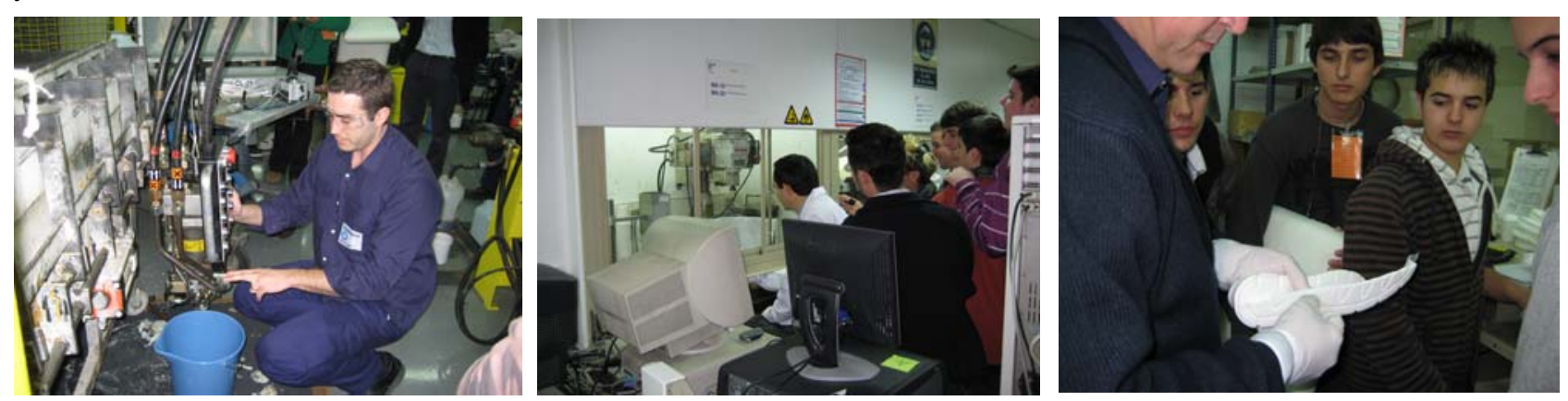

Les activitats de síntesi no es plantegen com a receptes a seguir, ja que un dels objectius del projecte és fomentar la creativitat i l'originalitat per donar resposta al problema plantejat.

\section{Propostes de Preguntes Guia}

Algunes de les propostes de treball proposades per a les visites estan orientades a fer que l'alumnat respongui interrogants del tipus:

- Què necessites per a fabricar una peça de poliuretà?

- Com s'obté una peça de ferro que tingui un cert ús?

- Com es fa el cable elèctric?

- Com il.luminaries la teva aula i la pista d'esport de l'institut?

- Com t'imagines el cotxe del futur?

- Com es fan les rosques dels capçals dels llapis portamines? una botiga de roba?

- Quins artefactes poden fer més confortable el viatge als astronautes?

- Per a què s'usen les matemàtiques en la indústria del metall?

- Com es coordina el control dels trens?

- Quins usos podem donar al paper reciclat en funció de les seves característiques?

- Com s'obtenen els tints i els colorants?

- Com dissenyar un tap per a un recipient perquè resulti pràctic, fàcil d'usar i fiable?

- De quines maneres es pot endurir el metall?

- Com s'aconsegueix l'estanquitat? Quina és la funció d'una junta?

El plantejament d'aquestes preguntes persegueix que l'alumnat es posi en la pell d'un enginyer o d'un científic i es trobi amb una situació possiblement real d'aquests professionals per tal de prendre consciència del que és treballar en aquest sector en alguns dels perfils d'estudis cientificotècnics que l'empresa necessita, des de llicenciats fins a FP de grau superior o graduats.
- És el mateix illuminar una pista de skate que 


\section{Model d'actuació}

En la creació del material didàctic per a les visites ha estat clau la cooperació tècnica entre:

- els generadors de la informació (personal del Centre de Recerca per a l'Educació Científica i Matemàtica -CRECIM- i professorat de Tecnologia, contactat a través del CESIRE AulaTec -Aula de Recursos de Tecnologia- del Departament d'Educació de la Generalitat de Catalunya)

- i els transmissors de la informació (professorat de Secundària i personal de les empreses que fan de guia al llarg de les visites a les instal.lacions).

Mitjançant aquesta cooperació s'ha elaborat un dossier de l'alumnat (i un del professorat) amb activitats adequades a l'edat de l'alumnat a qui va dirigit i amb uns objectius concrets d'aprenentatge.

Gran part d'aquesta metodologia del projecte està basada en experiències realitzades en altres països de la Unió Europea com per exemple una del Regne Unit (Ratcliffe i Westin, 2000) i a Finlàndia (experiències realitzades per la Universitat d'Helsinki, amb la qual el CRECIM manté un contacte regular).

\section{Resultats obtinguts fins ara}

Durant el curs 2008-2009 s'ha portat a terme diverses visites a empreses amb grups d'alumnat de diversos centres escolars, com a experiència pilot per tal de veure si s'acomplien els objectius marcats.

L'alumnat que ha visitat algunes de les empreses del projecte Prat de la Riba ha acollit amb ganes les propostes de treball que es plantegen en els dossiers. Les opinions recollides a partir de qüestionaris d'avaluació anònims mostren que no només els ha agradat el planejament del treball i la visita sinó que estan disposats a fer-ne alguna de diferent però canviant de sector.

Per descomptat, no podem treure gaires conclusions fins que haguem recollit més dades al llarg del curs per tenir-les avaluades pel juny.

\section{Conclusions}

El desinterès creixent dels alumnes per la ciència i la tècnica és una realitat a la qual hem de buscar solucions urgentment per diverses raons.

Primer, per una qüestió econòmica, ja que el mercat laboral actualment es troba mancat de per- fils professionals científico-tècnics (tant llicenciats universitaris com de formació professional de grau mig o superior).

Segon, per una qüestió d'igualtat de gènere, ja que hi ha una desigualtat molt gran entre nois i noies a les carreres cientificotècniques segurament relacionada amb les expectatives socials sobre les dones.

Una tercera raó és que els adults tenim la responsabilitat de transmetre als joves que conèixer $\mathrm{i}$ gaudir de la ciència o de la tecnologia és un dret que es pot exercir.

Només resta animar el professorat a participar en el projecte Prat de la Riba inscrivint l'alumnat a les visites a alguna de les diferents empreses col-laboradores $i$ així contribuir a fer possibles els objectius marcats.

Per a més informació podeu consultar la pàgina web www.pratdelariba.cat.

\section{Bibliografia}

Education Business Group West of England (2005). Work-related Learning for Achievement a prospectus of products and services. Doc. digital: http://www.n-

somerset.gov.uk/NR/rdonlyres/4DC18953-A61747E6-AC6F-

BAF673169CD7/0/document_20070711_EBGPr ospectusVersion2.pdf

IPWEA (Institut of Public Works Engineering Australia) National Board (2005) Attracting Young People' to Engineering. Document digital: http://www.ipwea.org.au/skills/AYP_Forum_Outc omes.pdf

OECD (Organisation for Economic Co-operation and Development) (2006). Evolution of Student interest in Science and Technology Studies Policy Report. Scribd, document digital: http://www.oecd.org/dataoecd/16/30/36645825. pdf

Ratcliffe, B. i Ulrica Westin, U. (2000). Educational Site Visits for Schools, document digital publicat pel CEFIC (European Chemical Industry Council):

http://www.cefic.be/files/Publications/EIPsitevisit s2000.pdf

Tots els documents digitals ha estat consultats al llarg del maig de 2009.

\section{Agraïments}

Agraïm en primer lloc a la Cambra de Comerç de Barcelona que a més del seu suport institucional 
ha patrocinat el projecte Prat de la Riba, cosa que ha fet possible posar en marxa el projecte.

Agraïm molt la col-laboració de totes les empreses participants que de forma desinteressada han contribuït a fer realitat el projecte Prat de la Riba: obrint les portes a l'alumnat de secundaria durant el curs, posant a disposició del projecte personal de l'empresa, ajudant a elaborar el material didàctic, contribuint així a millorar l'educació dels joves. I molt especialment fem extensiu l'agraïment a aquelles empreses que a més a més han volgut patrocinar el projecte: Lamp SA, Ferrocarrils de la Generalitat de Catalunya i La Farga Group. 